\title{
Acerca de la personalidad y el Carácter (1).
}

\section{1.-LA DEFINICIÓN Y DELIMITACION FENOMELÓGICA.}

Definimos la personalidad como el sistema de las dispesiciones individuales dominantes según el cual se ordena y manifiesta la vida anímica de cada sujeto en lo que respecta a su espontaneidad, a su impresionabilidad y a su modo de reaccionar distintivos, con cierto grado de coherencia y con mayor o menor conciencia e intención del yo. El análisis de esta definición nos permitirá ahondar en lo que of rece de inteligible nuestro peculiar ser anímico-espiritual, la entidad metafísica de cada hombre, en sí inalcanzable y cuyo estudio desborda la esfera del conocimiento psicológico y en general de la ciencia. Como es sabido, la personalidad es objeto de conocimiento de diversas disciplinas filosóficas. Es claro que aquí la consideramos sólo desde el punto de vista psicológico, sin llegar al extremo, preconizado por algunos investigadores contemporáneos, de atribuír a lá "caracterología" entiđad de disciplina independiente. El criterio en que se basa tal separación, según Helwig, es que la psicología investiga los procesos anímicos en sus relaciones internas, en corte transversal, con actitud indiferente

(1) El contenido de este artículo forma parte de un trabajo que aparecerí próximamente en forma de libro. 
respecto de las instancias anímicas y la valoración, mientras que la caracterología considera el alma en su enfrontamiento con la existencia, en corte longitudinal, en el conflicto creador de sus fuerzas con el mundo y en el valor positivo y negativo de sus manifestaciones. Pero la psicología que hoy se constituye y que nosotros tratamos de promover no sólo es fenomenológica, estructural y de superficie sino también dinámica, genética, integral y práctica, con lo cual desaparece la diferencia que se pretende erigir. Así determinada la materia de nuestro estudio, pasamos a examinar el detalle de la definición propuesta.

I. Que la personalidad sea el sistema de las disposiciones individuales dominantes, importa reconocer un fondo de constancia intrínseca peculiar/al sujeto que no se confunde con la totalidad de sus fenómenos anímicos. En efecto, mi personalidad es algo a la vez más estable, diferenciado, profundo y original que $\mathrm{mi}$ actividad consciente de cada momento, y. constituye un aspecto del conjunto de mi vida psíquica, aspecto formal por excelencia. Esto último es lo cue pretendemos significar al decir que la personalidad es un sistema, esto es, un modo o conjunto de tendencias 1 ectoras de la economía de la existencia individual. Todo estado c: acto psíquico se manifiesta como revelación de algo que preexiste, đe una condición nativa o potencia latente: el fenómeno no surge sino gracias a la actualidad de un resorte virtual de ser. Esta condición germinal es la disposición, facultad que esboza direcciones determinadas, medios de acción especiales y ámbito más o menos definido de vida arímica posible. Las disposiciones constituyen un sistema tanto por tener una base o fuente generatriz común, cuanto por hallarse en relación unas con otras de suerte que sus manifestaciones forman un conjunto en incesante proceso 
de integración. Este sistema varía de un sujeto a otro según la serie de las disposiciones que se destacan en lo que respecta a su calidad, su vigor y persistencia: tal es la contelación singular dominante de la armadura personal íntima.

2." El sistema de disposiciones que forma la personalidad tanto ordena cuanto pone de manifiesto el modo de ser de cada sujeto. Esto entraña una distinción de dos aspectos de la personalidad: el de superficie y el de fondo. En efecto, la personalidad se pone en evidencia a lo largo de la vida según las circunstancias del destino individual, sin que jamás se logre vaticinar con certeza qué resortes entrarán en función ante nuevas situaciones de importancia ni se pueda conjeturar cómo habría sido la conducta de una persona si las condiciones de su formación fuesen radicalmente distintas a las históricas. Lo que ya se ha puesto de manifiesto y lo que podrá ponerse en evidencia no concuerdan siempre o no concuerdan del todo. Estos dos aspectos guardan entre sí una relación comparable con la que existiría entre la $n a-$ tura naturata y la natura naturans, entre lo objetivado y la virtud creadora, entre lo explícito y lo implícito, ya que la vida vivida es cosa finita, inconmensurable con la vida, infinita en materia de posibilidades. La palabra "carácter" se aplica de ordinario con una y la misma extensión que personalidad. Como observa KLAGES, carácter puede mostrar un animal, una planta, hasta un objeto inanimado, pero sólo el hombre posee personalidad. KLAGES considera también que la personalidad es inseparable de la conciencia del yo, lo que es justo; mas, a nuestro entender, la particularidad esencial de ella es su índole germinal inexhausta. En condiciones óptimas el observador de fuera y el propio yo pueden aprehender las cualidades del carácter, positivas o negati- 
vas, y formar una idea más o menos realista de su entidacl, pero ni uno ni otro disponen de datos suficientes para abarcar en toda su riqueza los recursos de la personalidad no puestos aún a prueba por el destino. Por tales razones llamamos carácter, en sentido estricto, a la personalidad manifiesta, al porte adquirido.

3. La personalidad no es, como se la define ordinariamente, sólo el modo de reaccionar individual, ni consiste en la suma de diferencias de la mentalidad de un sujeto respecto de los demás o del término medio. Es inherente a la personalidad tanto lo distintivo de la espontaneidad y de la impresionabilidad cuanto la manera de reaccionar a las influencias externas de cada hombre. Aquí la impresionabilidad se refiere especialmente a la viđa afectiva, así como la espontaneidad y la reacción conciernen al dominio de las tendencias instintivas y la voluntad. Lo que se puede llamar el común denominador de estos aspectos de la actividad anímica es la experiencia vivida de la valoración que viene a ser como la causa final de los actos personales. Todo ser humano enfrenta la realidad con una actitud no puramente objetiva y neutral, sino con el alma abierta al mundo de lo atrayente $y$ de lo repelente: es impresionado fundamental. mente por aquello que la cosa o la situación le of rece de bien o de mal, por espontáneo movimiento apetece y realiza valores, y de esta suerte así como de manera reactiva ejecuta acciones significativas para su vida y para su espíritu cada uno según su propia y singular escala de predilecciones. Gracias a la actitud valorativa el individuo no sólo se inserta con nexos vitales en su ambiente circundante particular sino que con su estimativa se remonta también a la ordenación espiritual del munđo y de la existencia, en que cada cual tiene que cumplir decisiones absolutamente perso- 
jales. Descle este punto de vista la personalidad es, como postula Allers, "aquella ley de preferencia de valores basado en la cual el hombre individual ajusta su acción". Con semejante criterio la investigación psicológica ofrece la posibilidad de penetrar la verdadera naturaleza del carácter. Ciertamente, es un caminơ difícil de recorrer con éxito en la práctica, pero fuera de él no hav acceso a la substancia de la personalidad, lo que no ocurre con los métodos cle la psicología diferencial. En efecto, la verificación de diferencias o grados de variación individual en las diversas funciones psíquicas, sobre todo las más accesibles a los experimentos de laboratorio y a las pruebas de la psicotecnia, nada importante ofrece para el conocimiento real del carácter de un hombre determinado. La experiencia confirma a diario la esterilidad en esta matcria de los simples repertorios de diferencias según el tipo de la llamada "ectuación personal" y de las correlaciones establecidas sobre la base de la aplicación de cuestionarios. El núcleo de la personalidad es inaccesible a tales proceclimientos superficiales y mecánicos. "Esta psicología diferenciab trataode reconstruír aldindividuo a través de la yuxtaposición de atributos generales, pero con eso jamás llega hasta el individuo; lo que ofrece son meras piezas, falta el vínculo espiritual" (NorrL).

4. Decimos que la personalidad manifiesta cierto grado de_coherencia, lo cual equivale a reconocer en ella integración orgánica susceptible de ser comprendida. La conducta del hombre normal, a pesar de la complejiclad del conteniclo y de las formas de su vida anímica, con su accidentado comercio con el mundo temporal y las dificultades de su articulación con el del espíritu, muestra al observaclor una conexión fundamental e inconfundible, de manera que su conjunto representa la expresión más o menos imperfec- 
ta de una unidad. La personalidad encarna precisamente ese sistema unitario de la dirección general de la vicla animica subjetiva, ese régimen de constancia cualitativa en la movilijacl de la acción multiforme, esa cleterminación de la continitidad y la consecuencia de cáda ser humano a lo largo de sti historia. Como toda unielád viviente, la que nos ocupar carece del rigor propio de los contornos de uná cosa o de la coordinación de un sistema mecánico, y no excluye la variedad, las clivergencias y hasta los antagonismos intestinos. "Lì uniclad del alma humana - observa a este propósito Pfaender - no está constituicla por sus partes, órganos y territorios, sino que es el mismo fundamento portador de su.multiplicidad. Lá aniclad del alma es pues de hecho (no cn el orden temporal) lo primario frente a su multiplicidad". Esto no obsta parat que la unidad personal, ante todo unidacl de estilo, se perfeccione con nexos adquiridos en el curso de la existencia. La mismá formáción de la personalidad es un proceso gradual de afirmación de la vida animica unitaria: el niño pequeño carece propiamente de personaliclad; las disposiciones gue en él predominan son las varias y a veces discorclantes che dai simpleconstitución psicofísica, condicionada por la herencia. Sólo en el curso del desarrollo se esboza y define lá organización de la personalidad, hasta cierto punto sinterizanclo lo disperso y acordando lo clivergente de la plenitud original. Por eso las particularidades del modo de ser de un niño a menuclo son explicábles, mas no comprensibles. La susceptibilidad de comprensión del carácter es correlativá con la coherencia de sus manifestaciones. Incluso alrrunos psicólogos destacan esto como lo esencial. Asi Jaspens define la personalidad diciendo que es "cl conjunto de las relaciones comprensibles de la vicla anímica, variables de un individuo a otro", o como "el todo de 
las relaciones grenéticas comprensibles" de un sujeto. Nosotros no somos tan radicales. En nuestra clefinición hablamos de cierto grado de coherencia, lo que equivale a una comprensión relativa, pues en la dinámica de la personalidad intervienen tactores insospechados $y$ originales asociaciones de tendencias que muchas veces no se revelan ni al propio stijeto, auncune sea perspicaz en el autoanálisis. Asi, por ejemplo, el giro especial del carácter de una persona puede ser interpretado satisfactoriamente sólo con ayuda del conociniento de la vida del padre o de la madre, que mostrara la misma peculiaridad en la época correspondiente. Como veremos después, es innegable que hay manifestaciones gentinas de la personalidad dependientes estrictanente del patrimonio hercditario e ininteligible sin el conocimiento de los datos relativos al nusmo.

5. La mayor o menor conciencia $e$ intención del yo es el tiltimo aspecto de nuestra definición. En cierto modo, la personalidad tiene en el yo su centro, en el doble sentido de que, no $\sin$ limitaciones, domina la perspectiva del modo de ser personal y de que ejerce influencia determinante sobre la actividad de este. Yo me vivo a mi tnisno como entidad constante y punto de referencia en inedio del contenido cambiante de mi experiencia y yo también me vivo como agente determinativo de ciertas transformaciones que se operan en la economia de mi ser. No son por completo aislables una. de otra estas fases de la realidad subjetiva, pues la concienciá de si no sólo corresponde a una verificación estática del propio modo de ser, sino que entraña actos de nacientes autoconfiguración: lo que me parece que soy o puedo ser es yá una dirección para que yo, en cierto modo, sea asi de inmediato y activamente, con todas sus consecuencias. Esta influencia plasmadora es particularmente manifiesta en las 
graves situaciones, en los monentos críticos y decisivos de la existencia.

La relación del yo con la personalidad - que no es en rigor la relación de la parte al todo-tiene una serie de aspectos, entre los cuales deben señalarse los siguientes: el sentimiento de la personalidad, la conciencia de los valores personales, el conocimiento de uno mismo, el ideal de la propia persona, la autocrítica y el cominio de sí mismo. El sentimiento de la personalidad no clepencle tanto de la influencia directa de nuestras disposiciones nativas cuanto de la huella dejada por la experiencia relativa a la interacción entre nuestra personalidéd concreta y los acontecimientos de nuestro destino. Es un sentimiento, siempre algo vago, que se constituye y diferencia a lo largo de la vida, con períocios de equilibrio y períodos de inseguridad, con intensificaciones y debilitamientos, con ilusiones y falscamientos, tanto más auténtico cuanto más fundado en los efectos de la vida activa. Es difícil de distinguirlo del sentimiento de los valores de la personalidad. Como se sabe, estos son los valores más concrétos y diferenciados, de cuya plenitud y variedad apenas puede percatarse uno mismo. La revelación de los valores quie encarna la personalidad, al igual que el sentimiento de si mismo, depende en parte apreciable de las vicisitudes de la existencia, sobre todo de la educación, en que la valoración - explícita o implícita - que hacen de nosotros los demás es a veces de incalculables consecuencias. incluso para la constitución del carácter. $Y$ tanto la revelación o no revelación de valores personales cuanto la estructura de su conjunto - organizada en el curso de la formación espiritual del individuo - influyen sobre la autovaloración efectiva y a la vez son influídas por ella. De ahí que c) sentimiento de valer propio de un sujeto se confunda fá- 
cilmente con las manifestaciones de su afán de valer, el cual puede ser tanto mayor cuanto menor sea el propio valer real: el sentimiento intimo de una exigua significación personal obral en este caso como aguijón sobre las tendencias egotímicas, desenfrenándolas.

El conocimiento de tuno mismo, en el sentido psicológico, es un proceso cuya objetiviciad asequible - siempre limitada - depende de la aptitud para la intencionalidad reHlexiva $y$ del saber acerca del hombre en general. Aqui, como siempre, la aprehensión de lo individual es inseparable de la inteligencia de lo universal. Es una tarea forzosamente imperfecta, con un margen de ilusión qute nadie puede medir y cuyas ventajas y peligros escapan a la previsión. El procedimiento menos inseguro es el cotejo cle los propósitos y pronósticos subjetivos con la acción real en el curso histórico de la vida personal. El úmico experimento que cabe en esta materia es el preconizado por Goethe: "Trata de cumplir tu deber, y al momento sabrás qué hay en tî". La imper fección del conocimiento de sí mismo se comprtteba con 'ei hecho de que a menudo los clemás pueden prever con más acier to que tuno la conducta en tura situación determinada.

El ideal cle la propia persona, producto de las aspiraciones más intimas y de lo que se admira sin reservas en materia de bienes subjetivos, es la figura cuya presencia espiritual contribtye a organizar la actualidad de cada cual, por lo menos en situaciones particularmente importantes para Ta estima propia. Este icleal puede corresponder no sólo a los "leseos intimos sino también a las posibilidades de autorrealización. En este caso es el incentivo eficaz del desenvolvimiento armónico de la personaliclad. En el caso contrario, es sólo un papel que se anhela desempeñar, "un mito vivido" capaz de falsear toda la organización de la personalidad y 
su inserción en el munclo real. En lugar de aprehender bicnes auténticos y de situarse en la sociedad efectiva de los. hombres, el sujeto construye entonces un sistema artificioso de ficciones, que no ilusionan del todo ni al propio agente. La autocrítica sería el mejor antídoto contra tal desvi:tción, si la incapacidad para ejercitarla no fuese una de las concliciones del nacimiento de ésta. En efecto, la tendencia. al autoembelleciniento engañoso preclispone ya a juzgarse cradamente at sí mismo y a desconocer las efectivas posibilidacles intrinsecas. Igual cosa ocurre cuando intervienen condiciones de la personalided opuestas a las señaladas: desconociniento de la propia enticlad por exceso de autocrítica, dependiente de una valoración negativa o minimizaclora. de si, anexa al apocamiento o a otra condición a fectiva semejante.

La injerencia de la intención del yo en el funcionamien.to de la personalidad se mitestra cle manera revelante en los. actos de clominio de sí, de autodisciplina, de vencimiento interior, de autueducación. Con el ejercicio reflexivo de la, voluntad el sujeto determina la clirección de la actividacl personal conforme a exigencia del espiritu o a modelos de conciucta que reguieren oponer resistencia a determinadas tendencias, especialmente de, naturaleza vital.

\section{2.-ESTRUCTURA GENERAL DE LA PERSONALIDAD.}

La vida anímica toda funciona como una estructura y no como una suma de elementos; es una activiclad a la vez compleja y unitaria, cuyos fenómenos, estados y direcciones se relacionan y penetran recíprocamente en una totalidałl original. La personalidad presenta más acentuado este carácter orgánico, esta ordenación intima: en clla lo parcial se ajusta estrechamente al funcionamiento clel todo, y las 
fuerzas en juego manificstan sobresaliente jerarquia de planos. En efecto, aunque en la actividad psíquica general cle un individuo se relacionan la percepción, el pensamiento, la memoria, los sentimientos etc., el nexo no es tan intimo como -el que se advicrte entre los rasgos clel carácter. Esta diferencia puede expresarse diciendo que la iclea de unidad se cumple mejor en la conformación de la personalidad que en el resto de la vicla aninisica.

La estructtria general de la personaliclad se estudia desve dos puntos de vista: tuno analítico, que atiende a la distribución de las propiedades o rasgos en que putede descomponerse, y otro sintético, que mira a reducirla a un mínimum de conjuntos o planos de integración.

I. . Propiedad o rasgo es toda actitud definida inherente al sujeto y manifiesta en situaciones más o menos determinadas. No decimos que sea constante porque st1 manifestación ptede ocurrir tanto de manera continua cuanto frecuente o rara, según la naturaleza y las circunstancias. Lo csencial es que se muestra la misma en igualdad de circunstancias. Su regularidad se reconoce con la observación prolcngada del sujeto Jen condiciones múltiples. Hay rasgos de fácil verificación, por ser marcados, clominantes, estables o superficiales, y los hay poco asequibles a causa de su debilidad, de su dependencia, de su instabilidad o.de su profundidad. Es tarea del investigador, con resultados nunca definitivos, establecer la seric de propiedades del carácter, s11 graclación, el moio como mantienen su entidad y como se insertan en la estructura. Da idea de la multiplicidad de los rasgos el inventario hecho por Badargarten: "hemos llegado - clice - a scĩalar I629, de los ctiales 94 I son expresatos con adjetivos (en lengua alemana) y 688 con substintivos (igthalmente en alemél11). $53^{6}$ del número total tie- 
nen una existencia doble, como adjetivos y como substantivos, asi las expresiones caracterológicas propianmente dichas se reducen a 1093 ". Con respecto a la clasificación de las propiedacles del carácter todavía 110 disponemos de una plenamente satisfactoria. Entre las más sencillas y fundadas sobresale la de KLAGEs, que las distribuye en cinco grupos. con estos títulos: materia, trajuązón, cualidad, tectónica y aspecto. Examinemos lo esencial de semejante distribución.

a) La materia comprende todas las aptitucles o capacidades personales, como memoriá, comprensión, sagaciclad, fuerza de voluntad, tino etc. Se trata de dotes, tanto intelectuales cuanto del sentimiento y de la voluntad, cuya indole y cuyo vigor diferencian a cacta sujeto de los demás. Ia materia de la personalidad no es comparable con la tabula rasa, según lo pretendieron los estoicos antiguos y sensualistas ingleses, com si por naturaleza todas las mentes. f:resen iguales y sólo la educación y las demás acciones del ambiente imprimiesen las diferencias. Sin embargo, KIAAGes aprovecha tal metáfora comparandos la personaliclad de los diversos hombres lar tablas denmterial diferente: Ia de uno es como hecha de cera, la de otro como de madera, la de un tercro asimilable a la piedra etc., de acuerdo con la "huella" de las influencias cie fuera, cuya fuerza, forma $y$ persistencia varian con los sujetos. El conjunto de la materia del carácter es comparable también con un capital con el que se puede trabajar, transformando las aptitudes (salvo las afectivas) en habilidades. Es peculiar a esta clase de propiedades el hecho de que por sus consecuencias, se prestan a ser graduadas cuantitativamente por el observador:

b) La trabazón incluye propiedades estructurales como el alma abierta, inquieta, perturbable, sosegacta, templada, 
apagada o apática, la índole móvil y rápida o lenta e inerte. Estas propiedades no tienen una relación inmediata con las del grupo anterior; así, una voluntad fuerte puede acompañarse de un temperamento fogoso o frío. Si se parangona la trabazón con las propiedades de la substancia inanimada, se dirá que la vida anímica personal tiene densidad mayor o menor, fluidez grande o pequeña, tal o cual grado de consistencia, pues se refiere a disposiciones que deciden del curso o proceso de los cambios íntimos. Los efectos de esta clase de disposiciones también pueden medirse grosso modo, refiriéndolas a đos factores opuestos: impulsión y resistencia, cuya proporción es susceptible de figurarse en forma de cociente. De ahí que Klages llame a las disposiciones de trabazón propiedades proporcionales, y señale tres clases: a)

FT

la relativa a la voluntad, cuya fórmula: $\mathrm{EV}=-$, enuncia

$\mathrm{R}$

que la excitabilidad de la voluntad es directamente proporcional a la fuerza de las tendencias instintivas e inversamente proporcional a la resistencia; b) la correspondiente a la "Jorge Puccinelli ConvVS

afectividad, representable así: $\mathrm{ES}=-$, comporta que PS

la excitabilidad del sentimiento es directamente proporcional a su vivacidad e inversamente proporcional a su profundidad; c) la propia de la exteriorización, o sea de la expresión corporal voluntaria e involuntaria, que KLAGEs (introduciendo confusión en su propia nomenclatura) llama

$\mathrm{EV}$

"aptitud" de exteriorización, cuyo símbolo es $\mathrm{AE}=\frac{}{\mathrm{RE}}$, significa que está en razón directa de la excitabilidad de la 
voluntad y en razón inversa de la resistencia a la exteriorización. Lo esencial es que en cada uno de estos tres aspectos hay una constante personal de la excitabilidad. KLAGES relaciona en forma muy sugestiva las posibilidades de las constantes'a y $\mathrm{b}$, según que sea mayor el diviciendo o el divisor, con los tipos de la división clásica de los temperamentos. De estos nos ocuparemos en la parte concerniente a la tipología.

c) La cualidad - el aspecto más importante del carácter descle el punto de vista práctico -comprende las propiedades de dirección, por las cuales cada personalidad se mueve hacia fines determinados con mayor o menor intensidad y persistencia: es idiosincrásica una constelación privilegiada de móviles o "intereses". El sistema de los móviles comprende un gran número de disposiciones, que KLAGES divide en dos categorías: de liberación y đe sujeción, cada una de las cuales comprende tres grupos: móviles espirituales, móviles personales y móviles sensuales. Por lo demás, cualquiera amplia clasificación de las tendencias instintivas, de las inclinaciones yolas pasiones llena el mismo fin, siempre que tome en cōnsideración lal lactividadovolitiva, con sus diversas maneras de ejercicio según las características personales. Las consecuencias de la relacióni de los móviles entre sí puede ser comparada a la de las propiedades proporcionales. En efecto, cuando en la cualidad coexisten - hecho corriente - dos móviles opuestos, como en la trabazón, el resultado verificable se deberá, ceteris paribus, sea al poder de uno de eilos, sea a la debiiidad del antagonista. En general, hay cierta oposición entre los móviles de liberación (próximos al instinto) y los mọ́viles de sujeción (próximos a la voluntad y a la razón).

d) A la tectónica đe la personalidad pertenecen todas 
aquellas propiedades que son consecuencia de la relación existente entre los rasgos de los otros grupos. Las propiedades en general, según son ellas mismas y unas frente a las otras, en su original coexistencia, dan al conjunto nuevas propiedades que no son mero efecto de la adición: así surge el equilibrio, la proporción, la fijeza, la madurez y las características opuestas. Según esto, la personalidad puede tener una tectónica unificada, coherente, harmoniosa, otra la. tendrá falta de unidad asequible, discordante o hasta desgarrada; asimismo, hay texturas firmes, instables, marcacias, imprecisas etc.

e) El aspecto incluye las propiedades del carácter relativas a lo más exterior y manifiesto. Corresponden al aspecto modos de ser humanos tales como el del hablador, del jactancioso, del atrevido, del desenvuelto, del tímido, del lagotero, del entrometido, del devoto. Se trata de disposiciones de actitud o sea de rasgos esenciales de una especie determinada de la manera de comportarse. Estas propiedades del aspecto son incontables, principalmente a causa de sobresalir a la observación más superficial. De ahí que la descripción de los caracteres humanos comenzó con el aspecto. TEoFRASTO, autor de la primera obra sobre esta materia, según el fragmento de ella que ha llegado hasta nosotros, describe treinta tipos a base de otras tantas propiedades saltantes, casi todas relativas al aspecto. Las profesiones y las condiciones sociales, las épocas y las naciones contribuyen a su variedad. Sin embargo, conviene distinguirlas cuidadosamente de las falsas propiedades, apariencia engañosa de las efectivas.

2. La segunda manera general de estudiar la estructura de la personalidad es atendiendo a los planos de integracion. Pese a la unidad del ser humano, no todo es con- 
vergencia y cabal integración en su vida anímica. Por el contrario, en lo más unificado de la misma, la personalidad, existen propensiones divergentes, antagonismos y conflictos, infinitas formas de tensión, contraste y polaridad. La especulación metapsicológica se esfuerza vanamente en reáucir toda la multiplicidad de oposiciones y antagonismos intestinos a un dualismo simple: del alma y el cuerpo, đel espíritu y la vida, del yo y el ello, del instinto y la voluntad, de lo consciente y lo inconsciente - como si no hubiera contrariedad también dentro de cada una de estas entidades así como concordancias y colaboración entre los pretendidos extremos. La actividac psíquica of rece la paradógica coexistencia de unidad y pluralidad, la armonía de tensiones opuestas" (Heráclito). Aunque no hay par de aspectos capaces de constituír la fuente única de toda psicomaquia, es innegable que la vida anímica se relaciona con dos mundos diferentes: el corporal y el espiritual, entre los cuales se clivide lo que figuradamente podemos llamar su contacto. Este doble frente tampoco agota el origen de las diferencias intestinas, pero sí comprende gran parte de ellas. Tratándose de la personalidad, los planos correspondientes a estos frentes son el temperamento y el ethos. Muchos psicólogos no incluyen el temperamento en el dominio de la personalidad y mas bien lo oponen a ella o al carácter. Pero, siguiendo a Julius BAFInsEN y a otros investigadores, consideramos infundada la exclusión, y más aún, artificiosa e inconveniente. Sin las propiedades dependientes del orgánismo, el estudio de la personalidad perdería su base, de la misma suerte que el sacrificio del ethos lo privaría de su relieve. Semejante criterio es, sin embargo, explicable, pues elimina las mayores dificultades para tratar el carácter como un todo cerrado y homogéneo, dificultades que son el 
reflejo de una innegable polaridad de principios de ordenación: el de la dependencia đe lo vital y el de la orientación autónoma según lo intemporal. La idiosincrasia no se aprehende sin aceptar: esta distinción de planos, que es hasta cierto punto una abstracción, ya que la personaliđad se manifiesta en experiencias vividas, en actos, en expresiones y acciones cuya realidad entraña la integración del temperariento y el ethos en una síntesis siempre original e irreductible. Sin olvidar esta noción fundamental, cuya importancia relevaremos ulteriormente, consideremos aquí lo peculiar de cada uno de los planos.

a) El temperamento comprende, en primer término, las particularidades formales de la vida afectiva y su exteriorización: excitabilidad, fuerza, ritno y duración; en segundo lugar, la calidad o color de los estados afectivos vitales; $\mathrm{y}$, por último, la constelación individual de las tenđencias instintivas relacionadas con la vida del propio cuerpo. El temperamento es el plano pático de la personalidad; el sujeto lo vive pasivamente, como que en realidad no depende de la voluntad cambiarlo, sino refrenar sus manifestaciones $y$, con el concurso de la experiencia, hasta" cierto punto, fomentarlas y diferenciarlas de un modo determinado. La estructura de la personalidad en este plano es predominantemente causal (dentro de los marcos de la teleología de la vida), pues el temperamento se origina en la constitución: cada organismo humano tiene la suya, relativamente invariable. Sin embargo, el temperamento refleja no sólo la influencia de lo corporal, sino una tensión y un acordamiento entre lo fisiológico y lo anímico. Los médicos antiguos, desde HipócrAtes, derivaban el temperamento de los humores; los contemporáneos lo refieren a toda la actividad química del cuerpo y en especial a los sistemas reguladores de su econo- 
ría: el nervioso vegetativo y el de las secreciones internas. Esto es lo que Kraus llamó "persona profunda" y BraUn "persona vital", cuya doble faz recalca BürGer-PRINz: "por un lado el ser vital es vivido como cimiento motor y dinámico de la persona, con ese se ajusta a los marcos de estilo y a la ley de valor de la personalidad; por otro lado, de lo vital emana la unión inmediata con el mundo viviente en general, por ende, en lo ilimitado, la participación vital, según la excelente expresión creada para esto por PRINZHORN". La irivestigación moderna ha puesto de manifiesto que la constitución particular del sistema nervioso vegetativo y de las glándulas de secreción interna - que, como es sabido, tienen relaciones funcionales recíprocas - influye sobre el tipo de complexión y sobre la forma mentis, de modo que existe cierta correlación entre la figura corporal y el temperamento. Al ocuparnos de la tipología señalaremos lo que hay de más efectivo e importante en esta materia.

Descle un punto de vista general, es legítimo el concepto de una biotipología en que se considere las correlaciones químico-nerviosas entre lo somático y lo psíquico, pero es prematuro señalar una división anatómica del carácter, como quieren Kleist, Ewald y otros, localizando sus diversos aspectos en determinadas regiones del sistema nervioso central. Es igualmente infundado y simplista atribuir únicamente a la actividad de cleterminadas glándulas de secreción interna, como la tiroides, la paratiroides, la suprarrenal, las sexuales, la hipófisis, precisas e invariables repercusiones sobre la manera de vivir la experiencia y reflejarla en la acción. Ningún médico ignora hechos como éstos: que el hipertiroidismo, con el aumento del metabolismo de hase y lá excitación de la parte simpática del sistema nervioso vegetativo, acelera el ritmo psíquico y acrecienta la excitabili- 
dad de las emociones; que la mengua de la actividad de la corteza suprarrenal disminuye la resistencia al trabajo físico y mental; que la castración (en la mayor parte de los casos, no siempre) rebaja el tono de los sentimiento viriles. Pero sería insensato afirmar un perfecto paralelismo entre la actividad de las diversas glándulas del individuo y los aspectos de su idiosincrasia, y peor aún insinuar que con el conocimiento del "tipo endocrino de la personalidad" se puede "explicar el pasado del sujeto y predecir sus reacciones futuras, de las misma manera que con la fórmula química de un compuesto se conocen sus propiedades", según la temeraria tesis de Louis BERMAN (Th.c glands regulating personality, New York, I922). Con razón KroNfeld califica estas construcciones fantásticas de "metafísica endocrina". La falsa ciencia a la manera de BERMAN da al mundo una literatura abundante, uno de cuyos extremos más corrientes y lamentables es la prolija interpretación de los personajes a base de unos cuantos datos biográficos y algunos retratos. En oposición a tales excesos de la endocrinología popular se levanta la crítica de la verdadera endocrinología en estas palabras de Nicola PENDE: "las hormonas son tunos de los factores que regulan el desarrollo de nuestra personalidad, pero no crean nuestra constitución somática y mucho menos nuestra constitución orgánica, porque actúan en un terreno sobre el cual actúan también otras condiciones reguladoras. Ante todo, las hormonas actúan sobre los tejidos que, por su estructura y reactividad de origen hereditario y de ambiente, pueden responder o no responder a los estímulos hormónicos que llegan a ellos con la sangre, o responder de un modo cuantitativa o cualitativamente diverso de aquel que scría cle presumir según la acción fisiológica conocida de las diversas hormonas. Además, las hormonas actúan sobre los 
tejidos en colaboración por lo menos con otras tres condiciones reguladoras de los tejidos mismos: la condición neurovegetativa...., las vitaminas...., en fin, no podemos excluir una condición reguladora de la vida de todos los tejidos influidos por las hormonas, y sobre todo una condición reguladora de las funciones más altas del cerebro, o sea ese quid misterioso que llamamos conciencia o psiquis".

b) Así como el temperamento es la región de la personalidad relacionada íntimamente con el propio cuerpo, el ethos (2) constituye la esfera de comunicación con el mundo ambiente, abierta a la influencia del espíritu, influencia que se hace sensible, "espíritu objetivado", gracias al proceso de la cultura. Según esto, el "ethos" comprende la estimativa y la voluntad en su variante personal. El "ethos" es gnóstico, se dirige a los objetos según direcciones determinadas por la intuición de las esencias. Aunque no puede existir y obrar sin las tendencias del temperamento, tiene el poder de orientarlas, promoverlas y sujetarlas a las normas que aprehende. Gracias a su intervènción, el hombre tes capaz de actitudes y porte consecuente conuelejercicionderla libertad y la conciencia de ser responsable frente a los acontecimientos que le depara la realidad natural y cultural. Cada persona enfrenta s11 ambiente y las situaciones de acuerdo con las peculiaridades de su estimativa y de su voluntad, tan constantes como las psicofisiológicas de su temperamento. La estimativa varía de un individuo a otro en una serie de aspectos, entre los cuales se destacan: la perspectiva de valores asequibles, el sis-

(2) Usamos este término en el sentido caracterológico y no en el estrictamente moral. "Ethos" se ha usado descle la Antiguiedad como equivalente de "carácter"'. Según parece, ya Hifríclito lo emplé en este sentido, como la parte espiritual del alma individual. 
tema de preferencias, la tendencia valorativa dominante, la jerarcuía de los valores y el sumo bien o fin tiltimo, la concepción de la vida. Las características personales de la voluntad son inseparables de la estimativa, pues ésta le ofrece el sistema peculiar de motivos, que no es otra cosa que "la valoración individual efectiva o dirección habitual de valor. que guía la autodeterminación del hombre" (SPRANGER). Sin embargo, aparte de la amplitud y el orden personal de los motivos, el ejercicio de la voluntad depende en cada sujeto cle varias condiciones intimas, idiosincrásicas, algunas de las cuales son de considerable importancia, como la mayor o menor presteza para la decisión y la ejecución, el grado de autonomia o heteronomía en la deliberación y la acción, la lersistencia en el esfuerzo, la fuerza de voluntad y el estilo diel querer. Estas ultimas requieren ser definiclas. La fuerza de voluntad es la aptitud para concentrar y ajustar el esfuerzo necesario para realizar los actos y tareas correspondientes a las exigencias de la situación y a los principios e ideales que profesa el sujeto, venciendo tanto las resistencias externas cuanto las internas. Dicho de otro modo, es la factttad de perseguir y lograr fines contrabajo antimo en actos volitivos originales yyo concmerals manifestaciones de querer abreviado, cébil o habitual. (3). La fuerza de voluntad no tiene nada que ver con el esfuerzo exterior ni con tina pretendida "cantidad de energía" empleada. LEssch ilustra esto con un simil acmirable: la voluntad actúa a la manera de una lente que concentra en un foco los rayos del sol que la atraviesan: así como la lente no es fuerza o energía sino tun aparato eficaz para convertir la luz en fuego, así la vo-

(3) Fide "Psicologia genern" y psicopatología de la roluntat", Revisin de Neuro-Psiquiatio, $1939, \mathrm{~N}, \mathrm{i}, \mathrm{p} .14$. 
lintad tampoco es una fuerza sino un instrumento formal de la acción. El estilo de la voluntad puede definirse como la manera particular del ejercicio del querer en lo que atañe ai ritmo de la prosecución y la actitud dominante, tanto íntima (impulsividad, contención, dominio de sí mismo, autodisciplina, rigor consigo mismo, adhesión a máximas etc.), cuanto externa (activa, resistente, impositiva, luchadora, pasiva, moderada, acomodatiza etc.). Al tratar de la tipología completaremos estos datos e indicaremos lo esencial acerca de la variedad etológica de las estructuras individuales en materia de estimativa.

La estructura del "ethos", a diferencia de la propia del temperamento, es una estructura comprensible descle el punto de vista de la configuración de los fines espirituales, del ajuste de la vida subjetiva al mundo de los valores, las ideas, las normas. Es una estructura cerrada y coherente, pues, según el principio formulado por Spranger, "en cada fenómeno espiritual está de algún modo inmanente la totalidad del espiritu".

A pesar de la diferencia de la estructura dominante en cada plano de la personalidad, no puede desarticularse uno de otro, pues se penetran íntimamente: cada uno es aspecto fundamental de toda la realidad anímica, aparente u oculto en las diversas manifestaciones de la vida concreta del hombre. Es ilustrativo el hecho de que Klages, pese a su tesis metafísica de que el espíritu es adversario del alma y de la vida, acepte que en el hombre no hay ningún sentimiento que carezca de color valorativo. Mejor dicho, el análisis descompone la integridad del carácter como si el alma racional y el cuerpo no constituyesen una unidad en el ser del hombre, siendo así que existe un recíproca dependencia cualita- 
tiva entre ambos: "ipsam dispositionem corporis sequitur. dispositio animae rationalis" (TOMÁS DE AQUINO).

Esto nos lleva a examinar un inconveniente de la distinción de sólo dos planos - temperamento y "ethos" cn la estructura de la personaliclad. Algunos partidarios de la estructura estratigráfica distingue tres planos. Así, HoffMANN considera como plano intermedio entre el de las tendencias vitales y el del espíritu, el anímico de los sentimientos que tienden hacia objetos determinados; y RoTHACKER coloca entre el estrato del yo y el del ello, el de la persona, tormado en el curso de la vida por el influjo del yo. Este plano medianero tiene la ventaja de contener en sí aspectos del carácter que no se pueden adjuclicar de modo concluyente ni al temperamento ni al "ethos", como son las tendencias instintivas y los sentimientos dirigidos que no atañen al propio cuerpo ni a valores espirituales. LERSCr, quien distingue sólo dos planos, adjudica al que sirve de base a la personalidad, "fundamento endotímico", tanto los estados afectivos corporales y vitales, cuanto los del yo y los dirigidos o motivados, y las tendencias transitivas así como las reflexivas; en cambio, en la "superestructura de lai vida anímica" sólo comprende la voluntad y la "superestructura noética" (pensamiento e inteligencia). Sin embargo, en todas estas distribuciones, como en la nuestra, siempre subsiste el problema de deslindar los planos. Lo esencial es distinguir, en cada manifestación concreta del sujeto, lo que es claramente propio de cada plano definido y lo que queda en situación dudosa.

\section{3.-EVOLUCION DE LA PERSONALIDAD.}

La personalidad se estructura en el curso de la vida individual a partir de un confuso estado original de impresio- 
nes, tendencias y acciones elementales, bastante inconexas desde el puno de vista psicológico. Aunque tempranamente el individuo manifiesta un modo de ser peculiar, en el devenir de su existencia experimental metamorfosis, ora gradulales, ora bruscas, que no son meramente circunstanciales ni al azar. Al contrario, su conjunto aparece en parte apreciable como un proceso de crecinniento, de diferenciación y de configuración. Todo hace pensar que el despliegue de la personalidacl en el tiempo compone una formación con sentido orgánico, con su ley propia, de modo que clesde el principio hasta el fin obrase una finalidad trascendente a la composición de cada etapa. Sin embargo, ntestros conocimientos todavía son muy vagos en este dominio de la psicologia, pese a la importancia de los hechos y a la enorme especulación evolicionista de todo un siglo. Por eso hemos de contentarnos con esbozar algunas indicaciones generales acerca de los modos de variación de la personalidad en el curso de la vida, de la unidad formal de su desenvolvimiento y de los períodos en çue éste se divide.

r. La personalicate entraña un equitibrio sientpre móvil en que aparecenentevas condiciones para la manera como el sujeto se siente a sí misno, determina su acción y se cleja influir por el ambiente. En este dinamismo debe distinguirse ante todo las simples fluctuaciones de la verdadera metamorfosis del carácter. La fluctuación o alternación de meros estados del modo de ser individual, se debe al ritmo fisiológico de la constitución y a la periodicilad de las tendencias instintivas: se trata de una sucesión más o menos previsible de estados de ánimo y de modos de espontaneidlad o reacción, que se repiten en orden y tiempo a menudo invariables. De manera menos característica, las fluctuaciones pueden ser debidas a la repercusión de los aconte- 
cimientos exeriores sobre el "ethos" o a fases de su maduración.

La verdaclera metamoriosis, o cambio irreversible de là estructura del carácter, tiene dos formas: la modificación y la crisis. La modificación, transformación progresiva y más o menos imperceptible, se debe tanto a procesos enclógenos del temperamento cuanto al despliegue de la estimativa y al ejercicio de la voluntad. Aquí la predisposición decide el resultado, no sin la participación de la experiencia, pues con ésta la personalidad adquiere carácter histórico: la adquisición de nuevo contenido, la asimilación de lo objetivo por lo subjetivo, repercute diferenciando específicamente el sello personal, según veremos con más precisión en la parte de la dinámica del carácter.

La crisis puede compararse a una revolución, tanto por la intensidad de los fenómenos cuanto por el peligro que entraña para el equilibrio y el desenvolvimiento ulterior de la personalidad. Aparte de que todo desarrollo apareja la posibilidad de crisis, yoa aparte de que unos individuos son más . tpropensos que otros a sufrirlas, cada una de ellas puede ser criginada de manera inmediata principalmente por factores corporales, como la propia de la pubertad, o principalmente por factores espirituales, como la anexa a la desorientación valorativa por pérdicla de la fe. Lo más importante descle el punto de vista evolutivo es que estas conmociones pueden ser la condición necesaria para gue entren en vigor ciertas propiedades del carácter. Toda crisis comporta la quiebra de una disposición o un equilibrio de disposiciones hasta entonces firme y eficaz en la economía de la personalidad. "La situación de crisis - describe Heiss - se produce cuando sentimientos fuertes y definidos chocan con ntievos (e inconciliables) movimientos afectivos... No es el proceso de 
la transformación como tal lo que repercute, sino el becho de que en ese proceso desaparece tambićn una parte de nuestro yo vigente; perdemos terreno ańmico que poséimos, mientras que con el nievo sentimiento todavia no estamos nada ciertos de poder apreciar y seguir el movimiento del nuevo yo que surge, y de saber dóncle nos lleva". Mejor cute precisar que es un yo lo que desaparece y un yo lo que nace, sería decir que una forma anímica se rompe y otra pugna por sustituirla, pues es inherente al yo el conservarse en el canihio, así como variar en su persistencia.

2. Las metamorfosis del carácter tienen una dirección, un sentido determinado: realizan lá unidad formal de la personalidad en el tiempo. Pues el desenvolvimiento no consiste sólo en crecer en función con la edad y adquirir nueval substancia; consiste también en la formación de un orden en devenir, con la sncesión necesaria de etapas, cle suerte que lo propio de cada una de éstas no es la causa de la siguiente sino la expresión de la potencialidad cel conjunto, o, dicho en lenguaje iaristotélico, el despliegue de la personaliclad es manifestación de has cualidades inherentes a si antelequia como causa final" y formal. Esto no excluye la influencia del ambiente, sino que la presupone; toda evolución de la personalidad es ecológica, depende de las circunstancias naturales, sociales (muy especialmente de las familiares) y culturales. Esta influencia es destino para el sujeto tanto por sur repercusión del momento cuanto pur los modos de reacción que ha provocado en el pasado y las expectativas que crea para el porvenir. La actividad de las disposiciones puede ser promovida y acelerada, inhibida, dificultada o desviada por la acción del medio. Las últimas eventualidades no tienen forzosamente consecuencias definitivas, sobre todo en naturalezas vigorosas o respecto a dis- 
posiciones importantes, pues, según arguye Stern, "si determinados rasgos de una fase son reprimidos en su momento por las circunstancias exteriores - como el instinto del juego en la niñez, el examen de sí mismo en el comienzo de la pubertad-, entonces la entelequia interior de toda la persona puede hacer que tales fenómenos de desarrollo sean recuperados en un momento en que parece regir ya otra fase muy clistinta". Por otra parte, en la evolución de la personalidad, que es comparada muy justamente con una melodía, ciertas disposiciones desempeñan, por lo menos en parte, una función transitoria - declinan después de su expansión que cumple un fin-; en cambio otras se refuerzan continuamente por su propia potencialidad o por efecto de! ejercicio o el hábito. En fin, las propiedades adquiridas pueden no manifestarse explícitamente aunque sin desaparecer de la estructura de la personalidad: se hacen subconcientes. Ya FröBEL sostuvo que las primeras fases del desarrollo permanecen eficaces más tarde, y que el hombre hecho conserva algo de niño. En este sentido es legítimo distinguir el carácter actual de la personolialidad latente, así como afirmar un intercambio más o menos continuo entre ambos: a medida que aumenta la edad del sujeto crece la personalidad latente a expensas de la actual, cuyas reservas utiliza en ocasiones para las cuales no bastan los recursos del carácter manifiesto. El intempestivo vigor o la declinación inadvertida de ciertas disposiciones puede ocasionar una crisis especial de la personalidad. El hecho es que entonces el individuo vive subjetivamente la organización previa de su carảcter como si no hubiese mudado; y actúa según esa impresión engañosa. En este caso la conciencia de la personalidad - que JASPERS distingue de la conciencia del yo - resulta falsa, inaxlecuada, lo cual es capaz de desencadenar una conducta in- 
tempestiva y un círculo vicioso de reacciones perturbactoras del equilibrio animico.

3. Los grandes periodos evolutivos de la personalidad corresponden a los de la vida del hombre: la niñez, la adolescencia, la edad adulta y la senectud. La duración de cacta uno y de sus fases, asi cono sus peculiaridades, varian con la raza, el sexo, la constitución individual y el medio. Por eso la clad de nuestras referencias corresponde a un término nedio y los caracteres que señalaremos sólo serán los más generales y frecuentes en el individuo normal. a) No se puede hablar de personalictad en la infancia, apenas cle esbozos del carácter, pues el sujeto la adquiere gradualinente. En la niñ̃ez, a partir de los 2 años, se observa señales de intención en los actos, si bien donina toclavia, y hasta varios años después, la participación vital con los setes del ambiente, esto es, el predominio, en la experiencia vivida, de lo pático sobre lo gnóstico, (4) con diversas formas de identificación del propio ser, sobre todo en el juego, con las personas y las cosas. Hacia el cuarto año aparecen las manifestaciones de la llamada primera pubertad con la propensión at oponer resistencia a los manclamientos y prohibiciones, el afán de imponerse y la tendencia a la obstinación, persorificando en sí la autoridad cie los mayores. Al declinar la primera pubertad se prodtce tua fase de menor intranquilidad $y^{\prime}$ de menor egocentrismo, en que medra la aptitud para el esfuerzo personal, fase que aicanza su apogeo en la madurez del niño, la cual principia alredector de los 7 años. Sólo entonces se hace patente una relativa continuidad en la formacion del "ethos" : una actitud receptiva y comprensiva frente a los valores, con eficacia en la conducta, y manifestacio-

(4) Vide "Psicología general y psicopatología de la perecpeión", Actua7idud Médica Peruana, 1935, N." 4. 
nes con sentido de responsabilidad, esfuerzo en la labor seria y síntomas inequívocos de conciencia de las normas de la vida moral. Todo esto todavía hasta ,cierto punto dentro de las particularidades casi impenetrables del alma del niño, habitante maravillado de un mundo infinitamente valioso, cuya experiencia sui generis, intensa y efímera en cierto aspecto, con la frescura del primer contacto se abre a todas las signifiçaciones asequibles, sin distinguir bien lo objetivo de lo subjetivo, ni lo real de lo irreal y menos aún los valores, las normas y las leyes, de los seres y las acciones en que se encarnan. El niño vive sin mayor continuidad histórica, casi diríamos con eternidades sucesivas, un mundo no diferenciado en esferas sistemáticas y modos de ser definidos. Cumplidos los 9 años, comienza !a preadolescencia, que dura hasta el fin de los I2. Con el incremento de la conciencia (iel deber prospera la inclinación a la conducta práctica y seri:a, al par que desaparece el egocentrismo y el eudemonismo ingenuo. El deseo de saber, el interés por orientarse en la realidad inmediata, a la vez que la pasión por las cosas lejanas y el espíritu de ayentura, encuentran fácil camino, pues antes ha comenzado ya a manifestarse - $y$ progresa lentamente - la aptitud para distinguir lo efectivo de la ficción. En resumen, durante la niñez, época de gran plenitud interior, se oponen la fantasía y la adaptación a la realidad; alternan períodos de imitación çon un período medio de rebeldía y obstinación; y progresa gradualmente la intuición de los valores espirituales y su incorporación en la conducta, así como la tendencia al esfuerzo eficaz de uno mismo y cierto grado de conciencia de las propias posibilidades en la esfera de los principios, normas y exigencias ideales, aprehendidos más o menos esquemáticamente. En la preadolescencia - dominada por el sentimiento simple de 
confianza en sí mismo y đe fresca adhesión a la realidad la actitud seria ante la vida y el inquirir entusiasta sustituyen al juego y al ensueño mágico.

b) El segundo gran período de la evolución de la personalidad es la adolescencia, que dura aproximadamente descie los 13 hasta después de los 20 años. La personalidad se mo- difica entonces fundamentalmente con la aparición del instinto sexual y una nueva actitud frente al mundo y respecto del propio yo. La nota dominante de esta época, sobre todo durante la pubertad, es el íntimo sentimiento de inseguridad, de imperfección y de penuria subjetivas, unido o en conflicto con el afán de orientarse en las complejidades del propio ser, del mundo real y de la esfera espiritual, que se presentan al sujeto como otras tantas fuentes de problemas y de perplejidad. A la mentalidad plácida, unificada $y^{\prime}$ vuelta a lo externo, propia de la preadolescencia, sigue un estado espiritual inquieto, analítico y caviloso. El sujeto no se basta ya a sí mismo, anhela una entrañable relación con el alma ajena. Entonces se agudiza la conciencia de la propia personalidad y de la propia autonōmía SPranger llama a esta fase de "descubrimiento del yo" La desproporción y el conflicto son las características de casi todos los movimientos anímicos del púber. Luchan la vitalidad y el espíritu, la realidad y la utopía, la sujeción y la libertad el yo concreto y el yo ideal, el caos interior y la visión đel orden y la jerarquía, la sed de comunión y la proclividad al aislamiento, la auda-' cia y la timiđez, el entusiasmo y la congoja. La pubertad es también un período de desobediencia, obstinación y rebeldía, al principio mayormente en dirección transitiva, contra los demás, sin desmedro de una acentuada inclinación estimativa de los valores encarnados en las otras personas y de un impulso, no siempre consciente, de imitar a los modelos pre- 
fericlos. Al fin cle la pubertad la obstinación se vuelve mayormente reflexiva, dirigida contra sí mismo, aunque la valoración se endereza hacia el propio mundo interior y aunque el sujeto busca para sí la consideración ajena. Con el fin de la pubertad, alrededor de los 16 años, termina la crisis y se inicia una fase de relativa tranquilidad y coherencia, durante la cual se destaca la actitud de intención organizadora de la propia existencia conforme a un ideal, a la vez que con sentido práctico (la vocación, la forma de vida preparatoria de una ocupación definitiva). El joven intuye los valores, no sólo como forma sino como materia y contenido que tiende a incorporar, propende a adunar lo positivo y lo intemporal, a configurarse a sí mismo con la substancia que le ofrese el porte de las personas prominentes de su ambiente y los arquetipos de su panorama cultural. En este períođo de síntesis, el instinto sexual y el "eros" logran su adecuada conjunción en el caso de ser normal el desarrollo. En otro lugar hemos puntualizado la importancia de este proceso para el porvenir de la persona (5). Ahora sólo recalcaremos que la sensualidad tiene considerable importancia en la formación de la personalidad, no tanto comolinstinto raislado, cuanto por la manera como es vivida anímicamente por el sujeto de la misma suerte que la vida genital y amorosa del adulto recibe su sello del conjunto de la personalidad. Se ha exagerado mucho la trascendencia de los cambios somáticos en la evolución del adolescente, como si las inmensas transformaciones de su mentalidad fuesen simple reflejo de la actividad de las hormonas. Spranger ha refutado de manera lapidaria tal error. No repetiremos sus argumentos, pues basta señalar la circunstancia, bien conocida, de que en los

(5) "Psicología general y psicopatología de las tendencias instintivas"; Iicvista de Neuro-Psiquiatria, 1938, N." 3, pp. 319-320. 
casos de pubertas pracco.r, anormalidad que ocurre incluso en la infancia y los primeros años de la niñez, aunque se produce la metamorfosis somática de la pubertad - aceleración del crecimiento y aparición de los caracteres sexuales secundarios - no se presenta ninguna transformación animica comparable con los fenómenos de la adolescencia.

c) El largo período de la edad adulta comienza entre los 20 y los 24 años, a menuclo con una crisis, que Scriw iING llama la pubertad del adulto, acompañada incluso de cambios somáticos (como la aparición de las muelas del juicio). La personalidad del adulto ya no tiene el carácter preparatorio ni de metamorfosis de transición; sin embargo, en su transcurso se operan cambios evolutivos cuya esencia es llevar a la personalidad a su plena forma diferenciada. CFARLOTTE BüHLER divide la vida del adulto en tres fases: la primera que se puede identificar con la tercera pubertad de SCHMÈING, es experimentada como expansión, pero la vive el sujeto, más o menos implícitamente, como ensayo, como "actividad no especificada que se ejercita sobre el material vital", sin el carácter de la determinación definitiva del propio modo de ser. La segunda fase, de la "especificación de la intención vital", corresponde al apogeo de la personalidad, su estilo es el definitivo - como la concepción del mundo que abraza-, la eficiencia de la voluntad es óptima, con los mejores esfuerzos de rendimiento práctico: es la época de los frutos. La actividad eficaz frente a los hombres y las cosas predomina sobre el perfeccionamiento intrínseco. Este se logra, en las naturalezas con-capacidad para ello, en la última fase, de "objetivación", que en castellano tiene el apropiado nombre de edad madura, pues durante ella el hombre equilibrado puede alcanzar la más alta espiritualidad unida a la mayor cordura: la razón. Entonces persiste la actividad fruc- 
tífera, pese a los renunciamientos que impone el destino, pero dominada y trascendida por el máximum de rigor, ciisciplina y perfección formal de que es capaz el sujeto, con las pasiones templadas y el propósito vigilante de servirse de su experiencia de la vida y del dominio logrado en las tareas de su preferencia para elevar los quilates del ser íntimo.

d) El período de la senectud se caracteriza por la mengua de las disposiciones para la vida activa, la pérdida de las ilusiones respecto a las cosas de la tierra y la propensión a ocuparse del pasado personal. Sin embargo, no siempre tiene sólo estas características negativas. En las personalidades vigorosas y de calidad - de aquellos ancianos de los cuales Gracian ha dicho "que al paso que van perdiendo los sentidos, van ganando el entendimiento, tienen el corazón sin pasiones y la cabeza sin ignorancias" - se manifiesta como última labor del espíritu una nueva síntesis, una recapitulación de las reflexiones más entrañables, una visión del cosmos en su conjunto, un último ademán de suprema serenidad y comprensión.

Toda descripción de los periodos del desenvolvimiento de la personalidad entraña el peligro de sugerir" dos errores en cierto modo contrarios: el de pensar que se trata de un proceso lineal, ascendente hasta un punto y descendente después, y el de creer que las características de cada fase aparejan la eliminación definitiva de las cualidades de la anterior. Lo cierto está entre estos dos extremos. Como toda evolución, la de la personalidad es un proceso complejo en el cual lo nuevo de cada etapa entraña una síntesis, una integración estructural dinámica, a la vez progreso en una dirección y desmedro en otra $\mathfrak{u}$ otras; incluso en las últimas etapas de la vida humana surge algo posivamente original, no todo es en ellas involución. Por otra parte, el color de 
cada período se debe a que entonces nacen o se acentúan especialmente determinadas cualidades; pero esto no quiere decir que después desaparezcan totalmente. En el adolescente persiste no poco de lo característico del niño, y en el adulto no se borra lo que tuvo su esplendor en el joven. Con razón afirma MülLLER-FrenNFes que hay eterna niñez y eterna juventud en los hombres; ciertamente no de igual entidad en todos, y no siempre como personalidad latente o reprimida: "Son interiormente ricos y amplios los hombres que no pierden las cualidades de las etapas previas de la existencia, sino que, en el doble sentido que Hegel da la palabra aufheben, a la vez las superan y las conservan".

\section{4.-DINÁMICA DE LA PERSONALIDAd Y FORILACION DEL CARÁCTER.}

El examen del funcionamiento de la personálidad es una tarea forzosamente ilimitada, practicable desde muy diferentes puntos de vista. En primer lugar, se puede formar una idea de él atendiendo a las distintas funciones psiquicas que intervienen principalmente en la promoción de la vida activa y que, en general, porlvariar de un individuo a otro, son capaces de determinar el sello personal. Esto entraña una descripción prolija de las posibles diferenciaciones y acentuaciones de las diversas formas de actividad psíquica, especialmente de la vida instintivo-afectiva y de la voluntad, lo cual no puede ser expuesto sino en la extensión de todo un volumen. La obra de Lersch corresponde típicamente a este criterio. Otro punto de vista es el del estudio de las constela= ciones dinámico-estructurales que permiten şeparar caracteres más o menos determinados - lo cual, en rigor, es tema de la tipología. Un tercer criterio es el anexo a la consideración del dinamismo de la personalidad destacando la impor- 
tancia de sus factores más activos en lo que atañe al efecto senerador y configurador de la idiosincrasia. Siguiéndolo se corre el peligro de confundir la descripción de la economía de las fuerzas đel carácter, tanto con la explicación de las condiciones y causas que la determinan, cuanto con el proceso mismo del desarrollo de la personalidad. Semejante confusión ocurre en las caracterologías populares psicoanalíticas e individual-psicológicas. Una manera más de entender la dinámica de la personalidad (intermedia en cierto modo entre la anterior y la siguiente) es la que atiencle a la actualiclad de los procesos anímicos como direcciones nacientes $y$ suficientes. Allport la ha adoptado y perfeccionado con el nombre de "autonomía funcional de los motivos". Los "motivos" - entendidos en un sentido muy amplio, que se confunde con el de "experiencia" y "acontecimiento" — son significativos por ser del momento presente: aunque nazcan de "motivos" anteriores, a los cuales sustituyen, son funcionalnente independientes de ellos. "La motivación es siempre contemporánea... La vida de un árbol es continua con la de su semilla, pero la semilla Gá no sostiene y nutre al árbol plenamente desarrollado"-Aqú́c se trata de ama teoría generạl de la personalidad, de una especie de concepción epigenética de la vida anímica, no del simple camino que buscamos. Por último, el conjunto de la acción y los actos personales puede examinarse en función de los factores más importantes entre los que le dan forma y contenido inmediatos. Tal es el modo de ver la dinámica que seguimos aquí: la personalidad en movimiento, en su relación viva con lo que excita su actualidad y, por decirlo así, alienta y moldea sus disposiciones. Ciertamente, así es difícil eliminar del todo la confusión con el estudio genético del carácter. Pero, en principio, la distinción es clara: aquí tratamos de la formación 
del carácter en el sentido de la actividad que le da forma y contenido material - forma y contenido que influyen no sólo en la dinámica actual sino en la del futuro-, y no en el sentido de analizar y comparar la influencia respectiva de los factores internos y externos en la génesis del carácter, de lo cual nos ocuparemos después.

A pesar de la delimitación de nuestro punto de vista, la đinámica de la personalidad no deja de ser asunto inacabable. Para no perdernos en un mar de generalidades sin sübstancia o de datos válidos sólo para ciertas variedades del carácter, concentraremos modestamente nuestra atención en algunos aspectos de las reacciones, de las acciones espontáneas y de los ideales, y su trascendencia en el proceso que acostumbramos llamar "caracteroplástico".

I. Los acontecimientos del ambiente que obran como estímulo sobre la vida anímica, provocan en ésta reacciones cuya naturaleza varía según las disposiciones inđividuales, los antecedentes y el conjunto de la situación. El acontecimiento puede ser mero hecho exterior, aunque el sujeto tenga conciencia de él, o una verdadera experiencia llena de resonancia subjetiva. Los acontecimientos que se aproximan a este último extremo provocan reacciones importantes desde el punto de vista de la economía del carácter. Pero la entidad del acontecimiento y la anexa a la reacción no dependen estrictamente de los hechos objetivos, sino en función de la manera como el sujeto es susceptible frente a ellos. Esto es, que las situaciones son relativas tanto a lo objetivo, cuanto a lo subjetivo. Por eso la variedad de las situaciones es inmensa, no sólo respecto a calidad y riqueza sino en cuanto a profundidad y consecuencias. Ningún psicólogo puede menos que aceptar lo que a este propósito afirma Hartmann: "Nuestra vida humana, vista de cerca, no consiste en otra 
cosa que en una ininterrumpida cadena de situaciones que vienen y se van, descle las circunstancias fugaces y casuales ligadas al instante hasta los vínculos más íntimos, decisivos y duraderos que encadenan el hombre al hombre. La vida colectiva e individual arraiga en ellas y se refleja en ellas. Son el terreno en que surgen y tienden a decidirse los conflictos. Son el contenido de la esperanza y el desengaño, de la exaltación y el sufrimiento, la plenitud del corazón y la impotencia". Cada individuo, a lo largo de toda su existencia, es impresionado de manera peculiar por los hechos de su ambiente propio. De esta manera sus disposiciones pasan de la potencialidad a la actualidad según una constelación y un contenido de experiencia específicamente correspondientes a las influencias externas. La dinámica de la personalidad - tensa o laxa, rica o pobre, harmoniosa o desigual, con estas o aquellas direcciones - será en cierta proporción una respuesta al mundo circundante propio del sujeto, sobre todo a su mundo humano.

Pero las reacciones no sólo tienen la importancia de fenómeno actual que diferencia y estampa la vida anímica del individuo, no sólo su suma y sucesión histórica componen el contenido y los modos de manifestación del carácter; además de eso desempeñan a menudo el papel de principios o moldes de las reacciones futuras, especialmente en los niños y en los jóvenes. De ahí la importancia de las primeras impresiones en cada especie de experiencia de la realidad para el destino de las personas.' Esta repercusión "prospectiva" de las reacciones fué ya claramente reconocida por HERBART y su escuela: "cada reacción, una vez provocada por lo externo, guarda una determinada autonomía en el alma, una existencia en cierta forma y con cierto poder de mostrarse activa en el alma". En la actualidad, gracias al movimiento 
psicoanalítico - que dió un alcance ya excesivo a las primeras experiencias del individuo y cuyos representantes a menuđo atribuyen el carácter de causa a determinadas experiencias infantiles aparentemente eficaces cuanđo sólo son expresión de disposiciones innatas (acaso de personalidades anormales) y evolutivas-, nadie pone en duda lo esencial de la proposición herbartiana: que gracias a ciertos acontecimientos o a la repetición de especiąles influencias del medio, el sujeto adquiere determinada actitud que le predispone a vivir y conformar su comercio con el mundo bajo la especie y según las exigencias respectivas.

Burloud incluye estos hechos, así como la conversión de las formas percibidas en formas que perciben (después de ver varios objetos de la misma especie se adquiere el esquema correspondiente para identificarlos) y hasta algunos modos elementales de aprendizaje (a fuerza de oir cantar una melodía, aunque sea en tonos diferentes, me hago capaz de cantarla yo mismo), en un principio general que denomina de la "asimilación subjetiva". Según su definición, "toda forma sentida, percibida o pensada puede ser asimilada por el sujeto y convertida en una tendencia formatriz, en un esquema de acción". De este modo, "una combinación objetiva de cualidades formales más o menos realizadas a menudo, hace nacer una forma dinámica, una tendencia nueva. Gracias a este proceso, nuestras inclinaciones primitivas, en particular nuestras inclinaciones innatas, se complican y se diferencian". Esta última indicación tiene valor, pues, por una parte, ni las imágenes originadas por los estímulos ni los estados afectivos, como estados, son lo determinativo, lo dinamogénico, sino la tendencia, el acto intencional o dirigido por una intención, y por otra parte, la fuerza de la asimilación subjetiva no dimana del contenido tomado de fue- 
ra sino de la disposición psicodinámica individual. De ahí que dos sujetos, ceteris paribus, reaccionen a menudo de manera muy diferente ante la misma situación o que uno reaccione con efecto formativo y el otro no. La actitud personal reactiva recibe el sello de la experiencia vivida, pero ro el primer impulso; éste procede de las propensiones que inclinan originalmente hacia categorías de objetos o de actos cuyo común denominador es la capacidad de satisfacerla.

2. Al conjunto de la acción pertenece la actividad reactiva, cuyo dominio aumenta con la edad. La que consideramos en seguida es principalmente la acción espontánea, cuyas manifestaciones enriquecen también secundariamente la composición del carácter por el proceso del hábito y en general de los actos más a menos automáticos. Esto es, que la actividad espontánea, como la reactiva, tiene dos aspectos o momentos en la dinámica propia del individuo: el primero está constituído por los movimientos originales de la personalidad, voluntarios o no, que dan a la conducta la nota de novedad y frescura, y en los cuales el sujeto puede vivirse a sí como agente libre y creador; el otro aspecto consiste en que la actividad una vez espontánea, al repetirse, se hace gradualmente automática - sin que esto quiera decir que sta comparable a los movimientos de un autómata-, y acrecienta así el conjunto de resortes disponibles del carácter. Con esto aumenta también la estabilidad de su equilibrio dinámico, pero este equilibrio no depende sólo del predominio de las disposiciones ejercitadas, sino también de una actitud o facultad íntima, superior a las tensiones actuales y a la multiplicidad de las adquisiciones en el tiempo. A pesar de repetirse situaciones semejantes o típicas y, frente a ellas, modos de comportamiento también semejantes o típicos, no deja de manifestarse cierta espontaneidad en el ejercicio del 
dente sobre todo en el comercio social. Aunque el individuo con su mundo de cada instante, por lo cual las circunstancias y la acción tienen siempre algo de únicas. Esto es evidente sobre todo en el comercio social. Aunque el individuo en sociedad afronta situaciones determinadas - tanto más determinadas cuanto más íntimo, especial y homogéneo es el grupo humano en cuestión-, de manera inmediata se produce cada vez con cada una de las personas una situación peculiar por excelencia, que es de actitudes, valoraciones, propósitos y actos concretos, perfectamente individualizado, relación en la cual capta o cree captar no sólo lo externo de los demás sino actitudes, valoraciones, propósitos y actos íntimos dirigidos a él mismo; una relación plena y precisa de lo personal con lo personal, de la personalidad única con las personalidades únicas. Así, concretándose, se revela la forma dinámica de expresión de lo espontáneo e idiosincrásico en el condicionamiento de la situación.

El ejercicio de la acción espontánea, a diferencia de las meras reacciones, concentra y configura como un todo la vida anímica germinante $y$ difusa, plasmando el modo de ser empírico de cada hombre, su carácter, con las virtualidades de su personalidad. Gracias a tal ejercicio, las mismas tensiones y tendencias opuestas de la vida anímica personal pueden ser superadas en forma de integraciones eficaces, de nuevas y más libres actitudes. Como lo ha reconocido la sabiduría de todos los tiempos, el vencimiento y la represión de las tendencias instintivas es lo esencial en la dinámica de la personalidad y en la formación del carácter. "Pues la inhibición es precisamente sólo el medio de liberar las fuerzas para los fines positivos" (STERN). De ahí que dentro de la acción espontánea las operaciones de la voluntad se destacan como eminentemente caracteroplásticas; se destacan 
no sólo en cuanto los motivos ocasionales pueden constituirse en condiciones directivas y propulsoras de nuevos actos, formando parte de las adquisiciones durables del carácter, (6) sino, principalmente, por la disposición para la responsabilidad, inherente a todo querer libre, como lo prueban las investigaciones de $\mathrm{ACH}$. Según su definición, la disposición para la responsabilidad es la propia "del hombre inclinado a tomar sobre sí las consecuencias objetivas de sus acciones, a identificarse con ellas", constituye la "propiedad más amplia y valiosa del carácter, el medio principal de la formación de la voluntad y del carácter". La conciencia de la libertad es un hecho que vive todo hombre, incluso el materialista negador de la libertad en general, y con ella se constituye implícitamente otra realidad psicológica: la convicción de ser responsable de las propias acciones, que obra a su vez - ora conscientemente ora subconscientemente - como acicate poderoso y decisivo en la actuación personal, venciendo la inercia y las flaquezas de la carne.

3. Los ideales constituyen fuente substancial de estímulo y dirección para la dinámica de la personalidad y la consolidación del carácter.gEn general, es inherente a la personalidad el enlace del mundo real con el mundo ideal. Difícilmente hay acción, y hasta reacción, que no sea claramente determinada tanto por el ser cle los objetos cuanto por su valor. Más aún, el valor es esencialmente dinamogénico, es estímulo y meta de las tendencias. El hombre sólo persigue lo que entraña valores positivos y sólo evita los valores negativos o los valores positivos inferiores por preferir los superiores. Por otra parte, las tendencias, la voluntad, la acción son actos reales y vividos como reales aunque sean

(6) Vide "Psicología general y psicopatología de la voluntad". Revista de Neuro-Psiquiatria, 1939, N. ${ }^{\circ} 1, \mathrm{pp} .12-13$. 
promovidos por lo ideal. Pero lo que interesa considerar en relación con nuestro asunto no es toda la esfera de las esencias o ideas, sino los ideales, concebidos y abrazados más o menos explícitamente por el sujeto, cuyo contenido es la imagen de lo que debe ser el hombre. Los hay alcanzables y quiméricos, bajos y elevados, de significación transitoria o permanente, adecuados y no adecuados a la fase del descnvolvimiento de la personalidad, arraigados en la propia idiosincrasia y adventicios, auténticos y falsos. Se podría alargar más la lista de las variedades. Sólo nos referimos especialmente a un par: los ideales transitivos y los reflexivos. Los primeros representan lo óptimo de la vida humana en general; son admirados y anhelados como meta espiritual objetiva más o menos abstracta, universal y lejana. Los últimos figuran el desiderátum personal, son el acicate de las aspiraciones que el sujeto tience a convertir en programa o plan de su propia existencia. Los ideales, cualquiera que sea su cualiđad intrínseca, son realmente formativos si el sujeto los vive no sólo contemplativamente como formas superiores de la vida espiritual del hombre, sino activamente, corı fé, como asuncióngsubjetiva,l como tarea actual. En algunas naturalezas débiles es más eficaz la adhesión a un ideal aunque sea infantil o meramente inculcado, que la pérdida del mismo. Mas en general, la fuerza germinativa de los ideales depende tanto de su pertinencia respecto a la situación y las posibilidades personales, cuanto del desenvolvimiento de la estimativa con el pábulo de auténticos valores. Aunque toda sana formación de ideales supone selección e integración de valores en un movimiento progresivo - vencedor de lo que sólo es inercia de la adhesiones y preferencias previas-, es provechosa para el caráter si, además de esto, guarda pro.. porción con la metamorfosis que va operando en él y, en úl- 
timo análisis, con las disposiciones y aptitudes efectivas del individuo. De esto no hay que concluir que los ideales de la mayoría deban ser pegados a tierra, utilitarios, pues "en lo inútil como tal el hombre alcanza la justificación de su existencia, su aspiración y su penuria - ya que ambas nunca son lo último - así como sus pretensiones frente a la vida. Ahí da su antropodicea" (Hartmann).

Los ideales que se hacen fuerza viva del carácter son inseparables, por una parte, de las concepciones del mundo $y$, por otra, del cariño personal, con cuyas esferas se confunde la suya en gradación insensible. Las concepciones del mundo - cada cual tiene la suya - no son doctrina que el hombre escoge y compone al azar de las circunstancias y sólo por el ministerio de su actividad intelectual. Cuando son realmente personales, cristalizan y se adueñan del espíritu en virtud de potentes afinidades de lo más profundo del ser, y el ejercicio de la vida activa las pone a prueba y tiende a la incorporación práctica de sus consecuencias: JASPERS define sus dos aspectosiesenciales, de expresión efectiva y entrañable de la personalidad, y de imágenes objetivas racionalmente formadas, exigencias intelectuales que el sujeto exterioriza, aplica y utiliza como justificación. "Cuando hablamos de concepciones del mundo - dice - nos referimos a ideas, a lo último y total del hombre tanto subjetivamente. como experiencia vivida y fuerza de convicción, cuanto objetivamente como mundo de pensamiento configurado de manera concreta". "Las concepciones del mundo son ciertamente formaciones racionales cuando se formulan en las filosofías, pero no nacen por simple vía racional. Las concepciones del mundo sólo son realizables prácticamente, susceptibles de ser experimentadas y rebatidas. Todo lo teórico es sólo objetivación đe algo que previamente fué actuali- 
dad viva o movimiento puramente intelectual $y$ sin suibstancia. La vida es totalidad, todo lo teórico se mueve en fragmentos bajo las suposiciones, que no sólo tienen origen teórico". Según esto, lo importante de las concepciones del mundo para la dinámica de la personalidad y la formación del carácter es su cimiento subjetivo más que las nociones y el saber objetivamente válido, si bien esto último de ningún modo es indiferente, pues constituye el medio de expresión y el sentido de la actividad anímica. Cuando la concepción del mundo deja de ser una convicción viva, queda en la mente como simple construcción yerta y vacía, sin vigor para incitar eficazmente los movimientos de lá personalidad. El tono personal de la concepción del mundo depencle, pues, de la fé que la anina, la cual es militante mientras constituye un proceso en marcha, dirigido hacia algo que el sujeto experimenta como absoluto. "La fé es y será un riesgo, y en el fondo siempre es fé ciega" (IARTMANN). En conclusión, es un aspecto importante del "ethos" de una persona el sistema de ideas según el cual afronta la realidad. Gordon está en lo cierto al afirmar que "al hombre le es posible amoldare el aspecto espiritual de su personalidad de acuerdo con la filosofía de la vida que haya adoptado y, por consiguiente, adquirir esa organización del sentimiento y la fé con relación al universo, que es lo único que permite a la personalidad ser eficiente, completa y satisfecha".

$\mathrm{El}$ individuo humano vive incluído en la sociedad; es fondo importante de su experiencia de todo momento el ser miembro de una familia, de un grupo de amigos, de unáı clase social, de un círculo profesional, de una patria, con su realidad y su espiritualidad peculiares. Esta comunión de las almas tiene un aspecto particularmente significativo pará la formación del carácter: el cariño personal cuya esencia, re- 
conocida ya por los filósofos antiguos, ha siclo analizada de manera penetrante por HARTMANN, a quien seguimos en nuestra breve exposición del asunto. Este afecto, que constituye el vínculo trascendente entre los hombres, es poderoso por que arraiga en lo más profundo de la vida anímica. Gracias a su manifestación el sujeto revela aspectos - a menudo los mejores - de su ser, que de otra suerte quedarían latentes. Esto, unido al pocler de llegar a lo hondo del alma ajena y de percibir sus más altos valores y posibiliclacies de valor, hace del cariño o amor un agente poderoso para formar y desplegar los ideales, para fomentar el desarrollo de lo más eminente de la personalidad. El cariño, a menudo ciego para los valores manifiestos, tiene, por decirlo así, ojos iluminadores, pues la intuición emocional con que se actualiza revela en el objeto amado lo recóndito e iđeal cie su personalidad, valores que incluso pueden ser contrarios a los empíricos y ostensibles (acaso negativos). Piénsese, por ejemplo, en el cariño de la madre, a la vez adivinador de cualidades que medrarán más tarde y ciego para defectos del hijo, evidentes parai los demás. La situación amorosa tiene una vida con su ley propia, por encima del ser concreto de las personas que une, "nacida de la compenetración axiologica de dos puros complejos de valor con sus respectivas tendencias privilegiadas". El cariño tiende a despertar y a poner a su servicio todas las fuerzas espirituales de que es capaz el sujeto, con lo cual puede lograr acciones y transformaciones en concordancia con el ideal que descubre y acucia la persona determinativa, que "intuye lo perfecto en la imperfección". Dicho de otro modo, la relación amorosa creadora consigue, como muy pocas influencias de otra clase, aproximar efectivamente a su valor, a su quilate máximo, la personalidad empírica: es como una fuerza fecundante y 
promotora de metamorfosis en el sentido del perfeccionamiento. Es claro que el cariño no siempre y en todos los sujetos obra de esta manera, sobre todo si intervienen graves ilusiones y errores timéticos en las relaciones personales. Por otra parte, no es raro que el dominio tiránico de algunos valores generales (no personales) suplante al verđadero valor potencial de la personalidad, frustrando el desarrollo del "ethos" en germen. Entonces el sujeto, en cierto mocto, resulta desleal consigo mismo, con el ser que debería ser, y el cariño, un factor de adulteración. Apenas es necesario agregar que las mayores consecuencias caracteroplásticas de las vicisitudes del amor, como de los ideales, tienen su oportuni'dad en la niñez y la juventud, cuando la personalidad es más receptiva y. más plástica.

Honorio Delgado.

\section{Biblioteca de Letras}

